Article

\title{
Polypeptide Modulators of TRPV1 Produce Analgesia without Hyperthermia
}

Yaroslav A. Andreev ${ }^{1}$, Sergey A. Kozlov ${ }^{1, *}$, Yuliya V. Korolkova ${ }^{1}$, Igor A. Dyachenko ${ }^{2,3}$, Dmitrii A. Bondarenko ${ }^{2,3}$, Denis I. Skobtsov ${ }^{2}$, Arkadii N. Murashev ${ }^{2,3}$, Polina D. Kotova ${ }^{4}$, Olga A. Rogachevskaja ${ }^{4}$, Natalia V. Kabanova ${ }^{4}$, Stanislav S. Kolesnikov ${ }^{4}$ and Eugene V. Grishin ${ }^{1}$

1 Shemyakin-Ovchinnikov Institute of Bioorganic Chemistry, Russian Academy of Sciences, 16/10 Miklukho-Maklaya Str., Moscow 117997, Russia; E-Mails: shifter2007@gmail.com (Y.A.A.); july@ibch.ru (Y.V.K.); grev@ibch.ru (E.V.G.)

2 Branch of Shemyakin-Ovchinnikov Institute of Bioorganic Chemistry, Russian Academy of Sciences, 6 Nauki ave., Pushchino 142290, Moscow Region, Russia;

E-Mails: dyachenko@bibch.ru (I.A.D.); catameno777@gmail.com (D.A.B.); skob2000@mail.com (D.I.S.); murashev@bibch.ru (A.N.M.)

3 Pushchino State Institute of Natural Sciences, 3 Nauki ave, Pushchino 142290, Moscow Region, Russia

4 Institute of Cell Biophysics, Russian Academy of Sciences, 3 Institutskaya Str., Pushchino 142290, Moscow Region, Russia; E-Mails: kpd-88@list.ru (P.D.K.); Olga_rog@rambler.ru (O.A.R.); kabanovatata@mail.ru (N.V.K.); staskolesnikov@yahoo.com (S.S.K.)

* Author to whom correspondence should be addressed; E-Mail: serg@ibch.ru; Tel.: +7-495-336-6540; Fax: +7-495-330-7301.

Received: 14 October 2013; in revised form: 15 November 2013 / Accepted: 3 December 2013 / Published: 16 December 2013

\footnotetext{
Abstract: Transient receptor potential vanilloid 1 receptors (TRPV1) play a significant physiological role. The study of novel TRPV1 agonists and antagonists is essential. Here, we report on the characterization of polypeptide antagonists of TRPV1 based on in vitro and in vivo experiments. We evaluated the ability of APHC1 and APHC3 to inhibit TRPV1 using the whole-cell patch clamp approach and single cell $\mathrm{Ca}^{2+}$ imaging. In vivo tests were performed to assess the biological effects of APHC1 and APHC3 on temperature sensation, inflammation and core body temperature. In the electrophysiological study, both polypeptides partially blocked the capsaicin-induced response of TRPV1, but only APHC3 inhibited acid-induced ( $\mathrm{pH}$ 5.5) activation of the receptor. APHC1 and APHC3 showed
} 
significant antinociceptive and analgesic activity in vivo at reasonable doses $(0.01-0.1 \mathrm{mg} / \mathrm{kg})$ and did not cause hyperthermia. Intravenous administration of these polypeptides prolonged hot-plate latency, blocked capsaicin- and formalin-induced behavior, reversed CFA-induced hyperalgesia and produced hypothermia. Notably, APHC3's ability to inhibit the low pH-induced activation of TRPV1 resulted in a reduced behavioural response in the acetic acid-induced writhing test, whereas APHC1 was much less effective. The polypeptides APHC1 and APHC3 could be referred to as a new class of TRPV1 modulators that produce a significant analgesic effect without hyperthermia.

Keywords: sea anemone; analgesic polypeptide APHC; TRPV1 receptor; animal models; temperature regulation; nociception; inflammation

\section{Introduction}

The transient receptor potential vanilloid 1 receptor (TRPV1) is a nonselective cationic ion channel that is activated by a variety of stimuli: noxious heat $\left(>43{ }^{\circ} \mathrm{C}\right)$, protons, various lipid messengers and exogenous ligands, and most notably the pungent ingredient of chili peppers - capsaicin [1-3]. The TPRV1 receptor is believed to play a key role in temperature sensation and may be a molecular integrator for different stimuli [1,2]. TRPV1 receptors are primarily expressed in a population of small and medium diameter peptidergic sensory neurons called nociceptors, which can release proinflammatory and pronociceptive mediators and transmit nociceptive information from peripheral tissues to the spinal cord. Activation of the TRPV1 receptor in vivo sends an afferent pain signal to the CNS and releases pain mediators (substance P, calcitonin gene-related peptide (CGRP) and others), which lead to the development of local neurogenic inflammation [4].

TRPV1 is involved in the progress of different pathological states such as diabetic painful neuropathy, peripheral neuropathic pain, cancer pain, rheumatoid arthritis, osteoarthritis, chronic persistent cough, fecal incontinence, pain of the urinary bladder, cystitis and inflammatory bowel disease [5]. Thus, the isolation of natural compounds and the chemical design of substances capable of modulating TRPV1 are of great interest [6].

A number of small organic molecules were found to inhibit TRPV1 selectively at nanomolar concentrations in vitro, and some of the molecules have significant effects in vivo. For instance, a small molecular weight antagonist of TRPV1 produced positive pharmacodynamic effects, an increase in the heat threshold and a decrease in capsaicin-induced flare/dermal vasodilatation, in clinical trials [7].

Unfortunately, almost all small organic TRPV1 antagonists cause significant hyperthermia in animal models and a hyperthermic effect led to the termination of clinical trials for some attractive TRPV1 antagonists [8-12]. However, TRPV1 antagonists that did not block all modes of receptor activation and did not cause a hyperthermic effect were found [12,13].

Polypeptide molecules typically have a greater specific activity at a particular receptor than do small molecule agonists, which makes them attractive for researchers and pharmaceutical companies. We have previously reported the isolation of a polypeptide modulator of TRPV1 from a homogenized extract of the sea anemone Heteractis crispa named APHC1 and its partial in vivo 
characterization $[14,15]$. Two homological polypeptides (APHC2 and APHC3) were subsequently found in the same extract [16], but their biological activity has not yet been properly characterized. APHC1 and APHC3 are weak inhibitors of serine proteases [14,16] and modulate TRPV1-dependent normal and diabetic bladder smooth muscle contractility [17]. Here, we characterized the inhibitory action of the polypeptide APHC3 on TRPV1 receptor. We show evidence of the amelioration of the pain response by APHC1 and APHC3 in acute and chronic rodent pain models and we show the influence of both polypeptides on core body temperature in mice.

\section{Results and Discussion}

\subsection{Pharmacology of APHC3}

APHC3's mode of action was measured on HEK-293 cells using a whole-cell patch clamp approach and single cell $\mathrm{Ca}^{2+}$ imaging. Because APHC1 has been partially studied in a previous study [14], we did not analyze its effects on the capsaicin-induced current of the TRPV1 receptor. APHC1 has been shown to be a partial antagonist of capsaicin-induced TRPV1 currents with $\mathrm{EC}_{50} 54 \mathrm{nM}$. APHC3 is highly homologous to APHC1, differing in four of 56 amino acids. The positions of substitutions are shown in Figure 1. APHC1 and APHC3 have a primary structure that is highly homologous to $\mathrm{BPTI} /$ Kunitz type serine-protease inhibitors and $\mathrm{K}^{+}$channel blockers from sea anemones [18].

Figure 1. Polypeptides sequences for APHC1 and APHC3 aligned with BPTI/Kunitz type proteinase inhibitors from sea anemone Stichodactyla helianthus-SHPI-1 [19] and from bovine-BPTI [20,21]. Amino acids residues that differ from the APHC1 sequence are highlighted.

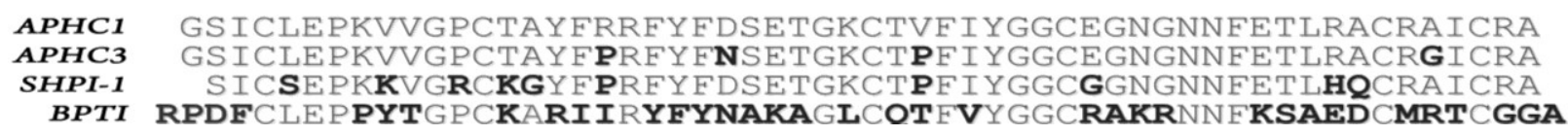

Several polypeptide modulators of TRPV1 that interact with the extracellular part of the receptor have been reported. Spider's polypeptides, the vanilotoxins 1-3 and DkTx, activate TRPV1 in vitro and mediate the pain response when injected in mice [22,23]. In addition, known rabbit polyclonal antibodies against the pre-pore region of TRPV1 partially inhibited receptor activation in vitro [24]. The structural homology of APHCs to these proteins is minimal so both polypeptides presented structural distinct class of TRPV1 inhibitors.

Compared to control non-transfected HEK-293 cells ( $n=5)$ (not shown), cells transfected with the pIRES2-EGFP/TRPV1 construct exhibited markedly increased sensitivity to capsaicin and low $\mathrm{pH}$, the stimuli known to activate TRPV1 (Figure 2). Given strong correlation between EGFP and TRPV1 expression, solely cells exhibiting high enough green fluorescence were patch clamped, and in some cases, stable recordings were achieved $(n=31)$. Although $100 \mathrm{nM}$ capsaicin elicited strong inward currents in all examined TRPV1-positive cells (Figure 2a), capsaicin responsivity declined with time in most cases (not shown). This phenomenon prevented from conclusive interpretation of long-lasting recordings required for assaying APHC3 effects on TRPV1 gating. Nevertheless, in four experiments, TRPV1-associated currents were firm enough to suggest the nearly $25 \%$ inhibition of TRPV1 currents by $300 \mathrm{nM}$ APHC3 (Figure 2a,b). 
Figure 2. Effects of APHC3 on recombinant TRPV1 expressed in HEK-293 cells. (a) Resting current recorded from a TRPV1-positive cell held at $-30 \mathrm{mV}$. Capsaicin $(100 \mathrm{nM})$ elicited transient inward currents that were partially inhibited in the presence of the APHC3 peptide (300 nM). Straight lines above the recording indicate application of APHC3 (Long line) and capsaicin (Short lines). The cells were stimulated and rinsed by rapid switching of the bath solution between the control solution and solutions containing the indicated compound. (b) Capsaicin responses in control and in the presence of the $300 \mathrm{nM}$ APHC3 peptide. In each case, the control response was calculated as an average of two acid responses recorded just prior to peptide application. Averaged responses recorded in the presence of APHC3 were normalized to averaged control responses. Those are presented as the mean \pm s.d. $(n=4)$. The inhibition of capsaicin-induced currents by APHC3 was statistically significant (Student test, $p<0.05$ ). (c, d) Cell responses to the acidification of the bath solution from $\mathrm{pH} 7.4$ to $\mathrm{pH} 5.5$ in control and in the presence of the APHC3 applied at different concentrations as indicated. The experimental traces in (c) and in (d, upper trace) illustrate representative responses of EGFP/TRPV1-positive cells. The bottom trace in (d) represents responses of an EGFP/TRPV1-negative cell assayed simultaneously. (e) Acid responses recorded in the presence of APHC3 (90, 160 and $240 \mathrm{nM}$ ) normalized to a control response. The data are presented as the mean \pm s.d. $(n=5-10)$. The inhibition of acid-induced $\mathrm{Ca}^{2+}$ transients by APHC3 was statistically significant at 160 and $240 \mathrm{nM}$ (Student test, $p<0.05$ ). In each case, the control response was calculated as an average of the two acid responses recorded just prior to peptide application. The average of the two acid responses recorded after peptide application was calculated and normalized to the control response. Experimental traces in (c, d) were obtained from three different cells. The changes in bath solution $\mathrm{pH}$ (continuous lines) and APHC3 applications (thick straight lines) are shown above the fluorescence traces. Cells were stimulated and rinsed by a rapid replacement of the control bath solution with modified bath solution at $\mathrm{pH} 5.5$ with or without APHC3.

a

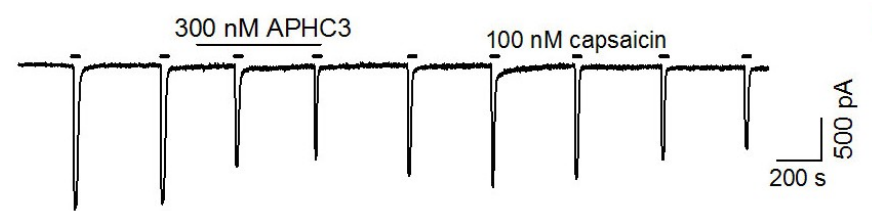

C

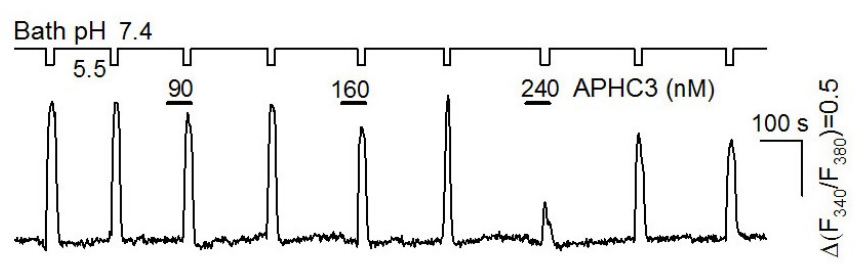

d

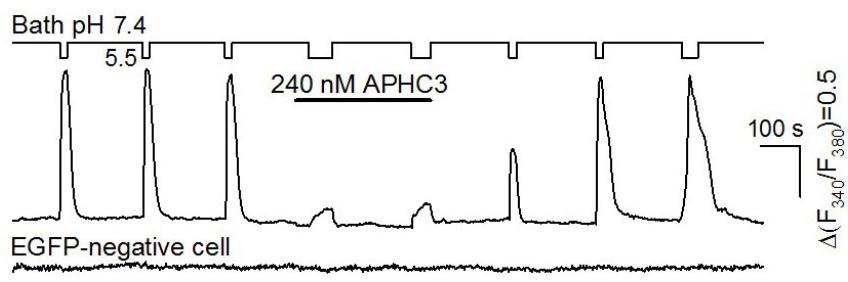

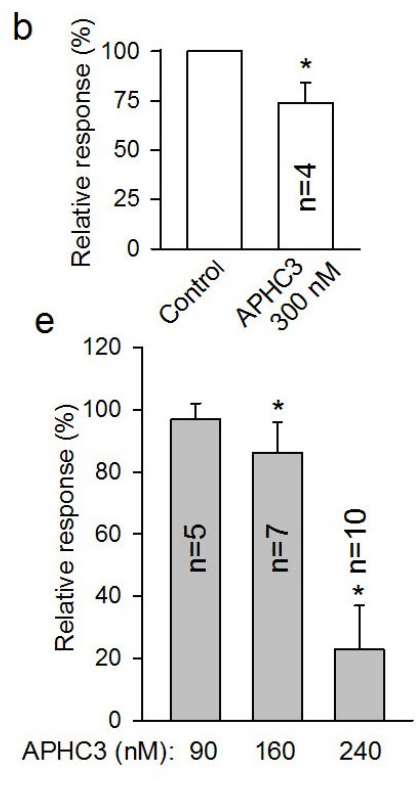


When TRPV1-positive cells were assayed using $\mathrm{Ca}^{2+}$ imaging, $100 \mathrm{nM}$ capsaicin elicited marked $\mathrm{Ca}^{2+}$ responses. However, at a serial and prolonged capsaicin application, $\mathrm{Ca}^{2+}$ responses were subjected to conspicuous rundown (not shown). Thus, capsaicin appeared to be an unsuitable agonist for examining effects of APHC3 on TRPV1 activity. Unlike capsaicin responses, short acidification of a bath solution could elicit robust $\mathrm{Ca}^{2+}$ transients in TRPV1-positive cells throughout 30-60 min recordings (Figure 2c,d).

Importantly, acid stimuli subtly or negligibly affected intracellular $\mathrm{Ca}^{2+}$ in control non-transfected HEK-293 cells $(n=11)$ (not shown) as well as in transfected cells that exhibited undetectable EGFP fluorescence, that is, insignificant TRPV1 expression (Figure 2d, bottom trace). Therefore, we studied effects of APHC3 using acid stimuli to activate TRPV1. At the same $\mathrm{pH} 5.5$, the magnitude of $\mathrm{Ca}^{2+}$ transients elicited by acid stimuli varied greatly from cell to cell, presumably due to different levels of TRPV1 expression. This inference is supported by the finding that acid responsiveness was in strong correlation with a level of EGFP fluorescence (not shown). The acid responses of TRPV1-positive cells were assayed in the presence of APHC3 applied at different concentrations. The fraction of cells that was capable of generating multiple stable responses to the same acid stimulus was low $(\sim 14 \%)$ as the response was liable to rundown. Therefore, APHC 3 effects on a given cell were only studied at the particular concentration of 90, 160, or $240 \mathrm{nM}$. Typically, cells were stimulated by 2-3 applications of the acid solution in control, in the presence of APHC3, and after washout of the polypeptide (Figure 2c). Only those cells that generated strong and stable responses in control conditions and after rinse of the polypeptide were used for the statistical analysis. Among the used polypeptide doses, APHC3 exerted statistically significant inhibition of acid responses at the concentrations of $240 \mathrm{nM}$ (by $77 \% \pm 14 \%)(10$ cells) and $160 \mathrm{nM}$ (by $15 \% \pm 9 \%)(n=7)$, while $90 \mathrm{nM}$ APHC3 was insignificantly effective $(n=5)$ (Figure 2c-e). The inhibitory effects of APHC3 were almost completely reversible (Figure 2a,c,d).

The residues responsible for APHC's activity are not determined. The four amino acid substitutions that distinguish APHC1 from APHC3 resulted in significant changes in the ability of these polypeptides to modulate TRPV1 activation. APHC1 inhibited $\sim 32 \%$ of capsaicin-induced currents at more than $200 \mathrm{nM}$ [14], while APHC3 had a lower inhibitory effect (25\%) even at higher concentrations more than $300 \mathrm{nM}$. For low $\mathrm{pH}$-induced TRPV1 receptor currents, we were unable to observe any effect of APHC1, whereas APHC3 significantly inhibited pH 5.5 induced currents (approximately $80 \%$ at $240 \mathrm{nM}$ ). These differences in pharmacology were expressed further in the in vivo results.

\subsection{In Vivo Effects of APHC1 and APHC3 in Pain Models}

Intensive studies of TRPV1 antagonists and knockout mice showed that this receptor plays a considerable role in many biological processes such as the perception of thermal stimuli, the development of inflammation, inflammatory thermal hyperalgesia and thermoregulation [4]. We conducted multiple in vivo experiments to assess the biological effects of APHC1 and APHC3, acting via modulation of TRPV1, on temperature sensation and inflammation. Possible negative effects of investigated components on the central nervous system were first excluded. We evaluated APHC1/3 in open-field locomotor activity tests as compounds capable of reducing locomotor activity could 
misrepresent results of other behavioral tests (particularly in pain models). We used one polypeptide dose $(0.1 \mathrm{mg} / \mathrm{kg})$, which was equal to the most effective polypeptide dose, in following in vivo experiments. There was no significant effect detected for either polypeptide at a dose of $0.1 \mathrm{mg} / \mathrm{kg}$ i.v. (Figure 3a). Locomotion tests revealed similar travelled distance and rearing compared with the saline control group. Thus, efficacy of polypeptides APHC1/3 in pain models did not resulted from locomotor impairment or sedation.

Figure 3. APHC1 and APHC3 did not influence normal mouse behavior but did change the behavioral response to thermal stimuli and capsaicin. (a) APHC1 and APHC3 did not significantly alter normal mouse behavior in the open field test at a $0.1 \mathrm{mg} / \mathrm{kg}$ dose $(n=9$ for each group). (b) Dose dependent inhibition of thermal nociception by APHC1/3 $(n=9$ for each group). (c) $0.1 \mathrm{mg} / \mathrm{kg}$ doses of APHC1 and APHC3 significantly reduced the behavioral response to capsaicin ( $n=9$ for each group). The results are presented as the mean \pm s.e.; $*-p<0.05, * * \ldots p<0.01$ versus saline group (ANOVA followed by Tukey's test).
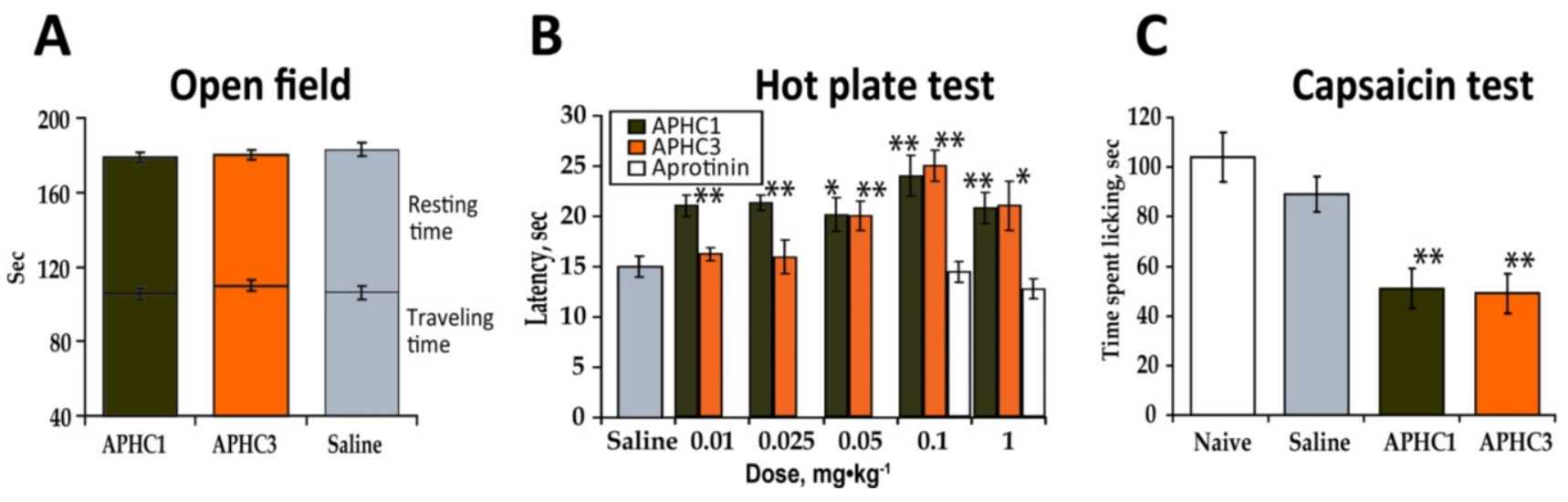

\subsubsection{Hot Plate Test}

The hot plate test is a most simple for TRPV1 inhibitor characterization since TRPV1 play significant role in temperature sensation. Effect of APHC1 and APHC3 on thermal nociception at dose $0.1 \mathrm{mg} / \mathrm{kg}$ after intramuscular, intraperitoneal and intravenous administration was measured before $[15,16]$. Each polypeptide significantly prolonged paw withdrawal latency at hot plate after intravenous administration. Here we assessed changes in thermal nociception to a noxious thermal stimuli elicited by different doses of APHC1 and APHC3 to determine minimal effective dose. Intravenous administration of APHC1/3 significantly increased paw withdrawal latency in a hot plate test. APHC1 was shown to be more potent because it produced antinociception even at a $0.01 \mathrm{mg} / \mathrm{kg}$ dose (Figure 3b). APHC1 did not prolong paw withdrawal latency at a $0.001 \mathrm{mg} / \mathrm{kg}$ dose (data not shown). Both polypeptides reached maximal effect at $0.1 \mathrm{mg} / \mathrm{kg}$. Potent serine protease inhibitor aprotinine with the same structural fold as APHC1 and APHC3 did not change behavioral response to thermal stimuli at doses 0.1 and $1 \mathrm{mg} / \mathrm{kg}$.

This observation of APHC1 and APHC3 reduction of the behavioral response to thermal stimuli, prolonging hot plate latency corresponds well with data on the behavioral output resulting from in vivo TRPV1 blockage or disruption of the trpvl gene [1]. Also it is important that this effect is not a result 
of their ability to partially inhibit serine protease since the most potent serine protease inhibitor aprotinine did not change behavioral response to thermal stimuli (Figure $3 \mathrm{~b}$ ).

\subsubsection{Capsaicin Test}

Because capsaicin is a selective agonist of the TRPV1 receptor, we tested the efficacy of APHC1 and APHC3 as TRPV1 receptor antagonists using the capsaicin-induced pain model. Intraplantar injection of capsaicin evokes pain-related behavior such as licking and shaking the injected paw. TRPV1 knockout mice are insensitive to the capsaicin test and most antagonists that block capsaicin-induced currents in vitro also block capsaicin induced pain-related behavior in mice [1]. Intravenous administration of APHC1/3 $(0.1 \mathrm{mg} / \mathrm{kg}) 15 \mathrm{~min}$ before capsaicin injection significantly reduced pain-related behavior. Both polypeptides showed an equipotent efficacy in $\sim 44 \%$ of response (Figure 3c).

\subsubsection{Formalin Test}

The formalin test is a complex in vivo model of pain where TRPV1's function is more integrative than perceptive. In the mouse, intraplantar injections of formalin produce a biphasic behavioral reaction. The molecular mechanisms underlying formalin-induced pain are based on tissue damage, non-specific activation of nociceptors and direct activation of TRPA1 receptors (measured in phase I) that drive the local neurogenic inflammation and CNS sensitization (measured in phase 2) [25,26]. APHC1 and APHC3 were tested on TRPA1 for inhibitory/activation effects. They showed neither agonistic nor antagonistic activity to this receptor as well to TRPV3, ASIC3, and p2X3 receptors at concentrations of up to $2 \mu \mathrm{M}$ in oocyte electrophysiology experiments or agonist-induced fluorescence readout assays (data not shown).

Administration of APHC1 $(0.1 \mathrm{mg} / \mathrm{kg}$, i.v. $)$ significantly attenuated the pain-related behavior in the first phase of formalin test (39\% of response) and more potently inhibited the second phase (70\%). In contrast, APHC3 injection at the same dose $(0.1 \mathrm{mg} / \mathrm{kg})$ almost completely inhibited $(86 \%)$ the second phase of the response but did not affect the first phase of the response (Figure 4a,b). When the dose of the polypeptides was decreased to $0.01 \mathrm{mg} / \mathrm{kg}$ no significant influence on the formalin-induced response was found.

An analgesic effect of a TRPV1 antagonist in formalin test was reported previously [27] and we could expect APHC1 and APHC3 to be efficient in amelioration of formalin-induced pain. It is interesting that at the same $0.1 \mathrm{mg} / \mathrm{kg}$ dose tested the two polypeptides produce dissimilar effects. APHC1 attenuated both phase 1 and phase 2 of the formalin nocifensive response, but although APHC3 had no significant effect on phase 1, it almost completely blocked phase 2. A possible explanation for this could be that APHC3 inhibits the response by blocking the $\mathrm{pH}$ mediated or modulated activation of TRPV1 that could occur during inflammation, whereas APHC1 blocks TRPV1 independently of $\mathrm{pH}$ modulation and is more efficient during the activation of nociceptors that occurs in phase 1 of the formalin test. Moreover since TRPA1 is co-expressed with TRPV1 in sensory neurons and their direct interaction has been suggested [28], APHC1 could affect TRPA1 activation via modulation of TRPV1. 
Figure 4. In vivo efficacy of APHC1 and APHC3 in inflammatory pain models. (a) APHC1 $(0.1 \mathrm{mg} / \mathrm{kg})$ significantly attenuated the first phase of the formalin test $(n=9$ for each group). (b) Both polypeptides $(0.1 \mathrm{mg} / \mathrm{kg})$ significantly inhibited the second phase of the formalin test ( $n=9$ for each group). (c) Dose dependent inhibition of CFA-induced thermal hyperalgesia by APHC1 and APHC3 ( $n=9$ for each group). (d) APHC3 $(0.1 \mathrm{mg} / \mathrm{kg})$ significantly reduced the number of writhes in the acetic acid-induced writhing test ( $n=9$ for each group). The results are presented as the mean \pm s.e.; $* * * \ldots p<0.001$, $* * \ldots p<0.01, * \ldots p<0.05$, versus saline group (ANOVA followed by Tukey's test).

A

Formalin test, Phase I (0-10 min)

B
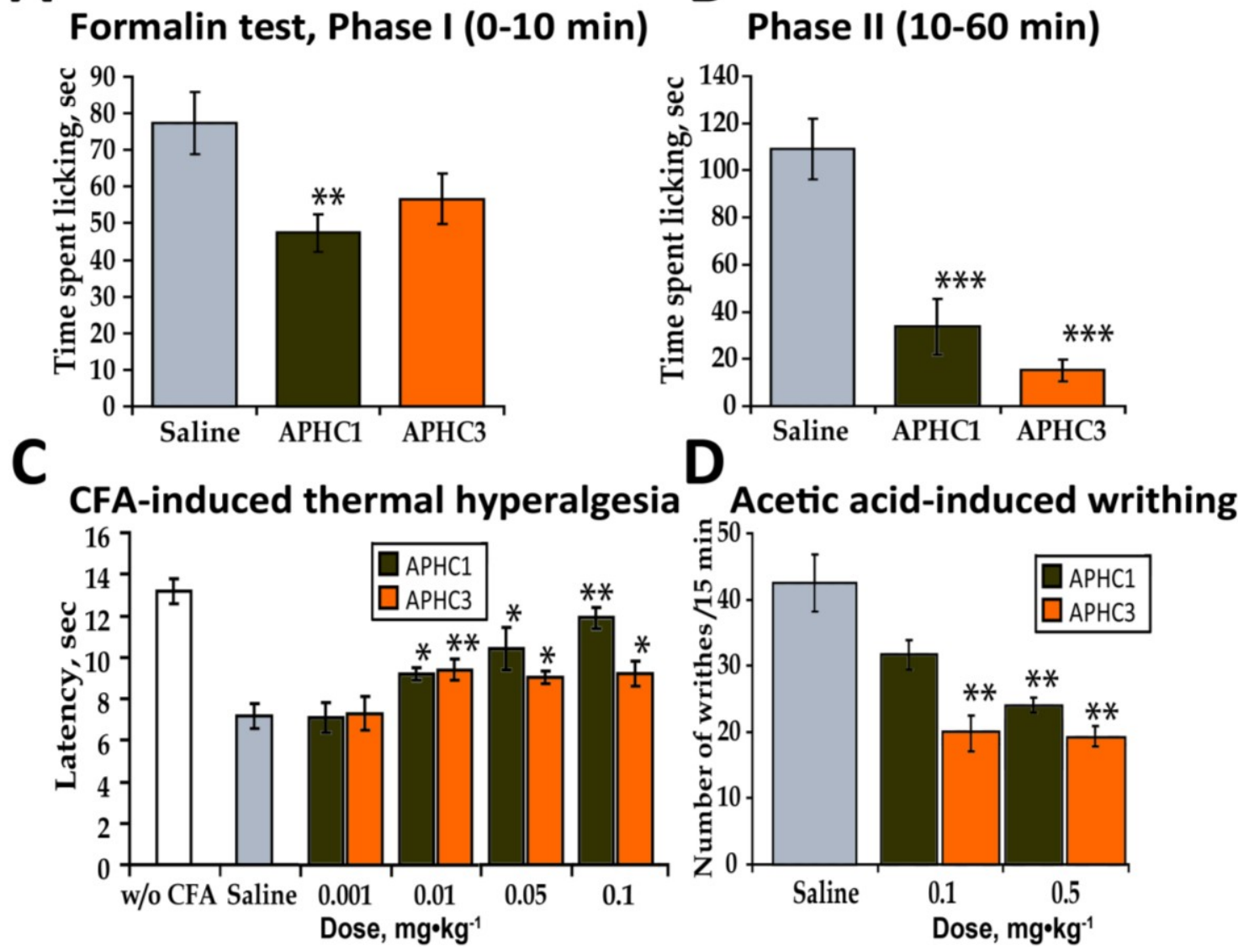

\subsubsection{CFA-Induced Hyperalgesia}

CFA-induced thermal hyperalgesia depends on TRPV1 activation; this was shown in TRPV1-deficient mice and using TRPV1 antagonists [29]. CFA-induced thermal hyperalgesia is a complex process where different inflammatory pathways acting via several mechanisms lower the TRPV1 temperature threshold and influence thermal sensitivity [30]. CFA-treated mice developed thermal hyperalgesia in the injected paw, this manifested as a decrease in the latency to paw withdrawal in response to thermal stimuli (Figure 4c). Both APHC1 and APHC3 significantly reduced thermal hyperalgesia by i.v. administration in doses $0.1-0.01 \mathrm{mg} / \mathrm{kg}$. The APHC1 effect was larger ( $\sim 80 \%$ of reversal) and was clearly dose-dependent. APHC3 had significantly lower efficacy (34\% of reversal). 


\subsubsection{Abdominal Constriction Test of Visceral Pain (Acetic Acid-Induced Writhing)}

TRPV1 can be activated by low $\mathrm{pH}$ stimuli and is therefore involved in pain caused by acidification, which can be measured in the pain behavior model of acetic acid-induced writhing [27,31]. Intraperitoneal administration of acetic acid provokes a very stereotyped behavior in the mouse. The constriction response is considered the definitive measure of visceral pain intensity [26]. Animals were pretreated with polypeptides $15 \mathrm{~min}$ before acetic acid injection. APHC3 administration ( 0.1 and $0.5 \mathrm{mg} / \mathrm{kg}$, i.v.) significantly reduced the number of writhes observed (50\% inhibition); APHC1 did not produce a statistically significant effect at $0.1 \mathrm{mg} / \mathrm{kg}$ (i.v.) but dose $0.5 \mathrm{mg} / \mathrm{kg}$ (i.v.) significantly reduced number of writhes observed (Figure 4d).

Usually, molecules that inhibit [27] or potentiate [12] pH-induced TRPV1 currents in vitro produce similar effects in vivo - they significantly reduce the number of writhes after acetic acid injection. This correspondence was confirmed by our results. APHC3 significantly reduced the number of writhes; APHC1 did not significantly inhibit the response to acetic acid at dose $0.1 \mathrm{mg} / \mathrm{kg}$.

\subsection{APHC1 and APHC3 Decrease the Core Body Temperature}

TRPV1 participates in thermoregulation, and almost all its known agonists and antagonists change core body temperature. Selective TRPV1 agonists, such as capsaicin, cause a significant decrease in body temperature. The influence of antagonists on core body temperature is more complex [13,32]. Antagonists that interact with the intracellular capsaicin-binding pocket of TRPV1 elicit a hyperthermic effect if they are able to inhibit pH-induced TRPV1 currents [10,12]. Antagonists that potentiate the $\mathrm{pH}$-induced activation of TRPV1 either decrease or do not change body temperature [12,32]. To date, the best explanation of this hyperthermic response, which occurs when an antagonist is administered, is that the antagonist's ability to inhibit the constantly activated abdominal TRPV1 receptors provokes a cold defense response [8,33]. However, the factors that keep the receptor in an activated state have not yet been identified. Modulation by $\mathrm{pH}$ was proposed as one of the more probable factor [13].

Admittedly, hyperthermia is considered a critical side effect of TRPV1 antagonists, so we assessed the effect of the polypeptides on body temperature. Polypeptides were administered intravenously at doses $0.1 \mathrm{mg} / \mathrm{kg}$ and $0.5 \mathrm{mg} / \mathrm{kg}$, and rectal temperature was monitored (Figure 5a,b). An antagonist AMG9810 produced hyperthermic effect was measured as a control (Figure 5c) and aprotinin was used as a control of serine protease inhibitor (Figure $5 \mathrm{~d}$ ).

Injections of saline or the vehicle used for AMG9810 (10\% DMSO in saline) did not significantly change the core body temperature of the mice. Administration of AMG9810 (an all modes antagonist of TRPV1) produced a significant increase of $1.6{ }^{\circ} \mathrm{C}$ in body temperature, as previously reported [8]. The serine protease inhibitor aprotinin, a polypeptide, caused an increase in core body temperature $\left(0.4-0.5{ }^{\circ} \mathrm{C}\right)$ that was not statistically significant when compared to saline group. In contrast to AMG9810 and aprotinin, both APHC1 and APHC3 at dose $0.1 \mathrm{mg} / \mathrm{kg}$ showed a hypothermic effect on the core body temperature of mice. APHC1 produced a rapid decrease in body temperature, $-0.8^{\circ} \mathrm{C}$ in the 30 min after administration, and the body temperature stayed at this level throughout the remaining 
data acquisition time. APHC3 caused a slow decrease in body temperature, reaching a change of $-0.6^{\circ} \mathrm{C} 60 \mathrm{~min}$ after administration.

Figure 5. Effects on core body temperature (rectal measuring). (a) APHC1 (0.1 and $0.5 \mathrm{mg} / \mathrm{kg}$ ) and saline ( $n=7$ for each group); (b) APHC3 $(0.1$ and $0.5 \mathrm{mg} / \mathrm{kg})$ and saline ( $n=7$ for each group); (c) AMG9810 $(30 \mathrm{mg} / \mathrm{kg})$ and vehicle (10\% DMSO) $(n=7$ for each group); (d) aprotinin $(0.1 \mathrm{mg} / \mathrm{kg})$ and saline $(n=7$ for each group). The results are presented as the mean \pm s.e.; $* \ldots p<0.05$ versus saline group (ANOVA followed by Tukey's test).
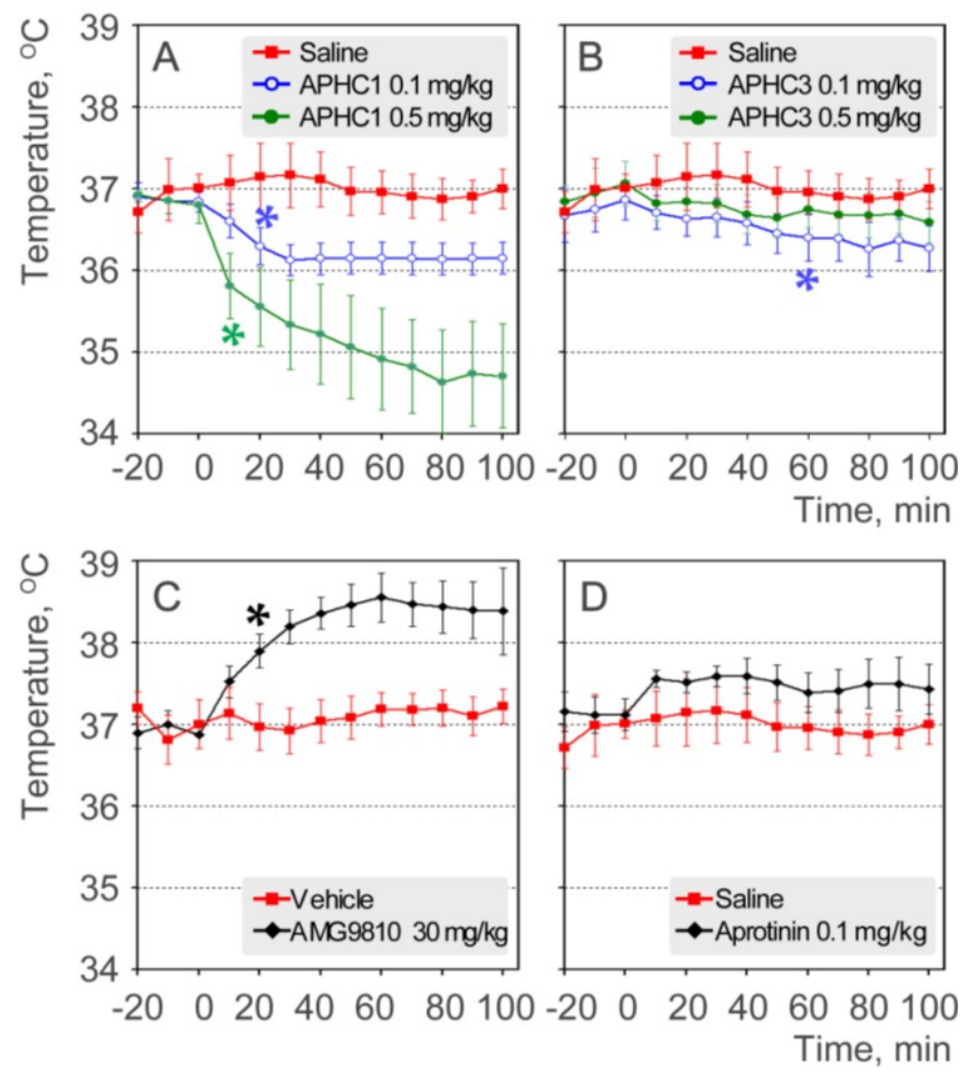

APHC1 at dose $0.5 \mathrm{mg} / \mathrm{kg}$ produced a more significant decrease in body temperature, $-2.1{ }^{\circ} \mathrm{C}$ at the end of data acquisition time. APHC3 at dose $0.5 \mathrm{mg} / \mathrm{kg}$ produced some hypothermic effect $\left(-0.4{ }^{\circ} \mathrm{C}\right)$ but effect was not statistically significant.

APHC1 significantly decreased core body temperature in both tested doses. APHC3 produced modest hypothermic effect despite it efficiently inhibiting $\mathrm{pH}$-induced TRPV1 currents. Therefore, we can conclude that in case of these peptides the ability to inhibit the $\mathrm{pH}$ activation of TRPV1 does not play a significant role in effect on thermoregulation.

Many different sensitized states of TRPV1 are predicted for organisms, both under normal conditions and in pathology. Currently, only a few of these conditions can be modeled in vitro because they may be induced by a combination of different factors, such as regulation by multiple protein kinase pathways, endogenous lipids, and extracellular environment ( $\mathrm{pH}$, temperature, osmolarity). We hypothesize that antagonists targeted to the capsaicin-binding pocket can efficiently inhibit tonically activated abdominal receptors, while APHC1/APHC3 cannot. Moreover, we can speculate that these 
peptides (especially APHC1) could potentiate abdominal TRPV1 since they significantly decrease core body temperature. Hypothermic effect of APHC1 and APHC3 was not the result of their ability to inhibit serine protease since the most potent serine protease inhibitor aprotinine did not change or modestly increase core body temperature (Figure 5d). The ability to decrease core body temperature could be a useful approach to obtain therapeutic hypothermia with additional analgesic (anti-nociceptive/anti-inflammatory effect) properties, as proposed for TRPV1 agonists [34].

\section{Experimental Section}

\subsection{Production of Recombinant Polypeptides}

APHC1 and APHC3 were produced as described previously [14,16,35]. Briefly, DNAs encoding the polypeptides were constructed from synthetic oligonucleotides using PCR and cloned into the expression vector pET32b+ (Merck KGaA, Darmstadt, Germany). Escherichia coli BL21(DE3) cells expressing TRX fusions of APHC1 or APHC3 were cultured at $25{ }^{\circ} \mathrm{C}$ for $12-14 \mathrm{~h}$, harvested, resuspended in start buffer for metal-affinity chromatography $(300 \mathrm{mM} \mathrm{NaCl}, 50 \mathrm{mM}$ Tris- $\mathrm{HCl}$, $\mathrm{pH}$ 7.5), ultrasonicated, and centrifuged to remove all insoluble particles. Fusion proteins were purified using a TALON Superflow Metal Affinity Resin (Clontech, Mountain View, CA, USA). HCl up to $0.5 \mathrm{M}$ and $\mathrm{CNBr}$ with a molar ratio to protein of 600:1 were added to the fusion protein solution in the metal-affinity chromatography elution buffer [35]. Cleavage was performed overnight (18 h) at room temperature in the dark. Reactions were terminated by drying the sample under a vacuum. The recombinant APHC1/3 polypeptides were purified on a reverse-phase column Jupiter $\mathrm{C}_{4}$ (Phenomenex, Torrance, CA, USA) $250 \times 10 \mathrm{~mm}$. The purity of target polypeptides was verified by MALDI-TOF mass-spectrometry.

\subsection{Cell Culture and Transient Transfection}

HEK-293 cells were cultured in Dulbecco's modified Eagle's medium (DMEM) (Life Technologies, Grand Island, NY, USA) containing 10\% (vol/vol) fetal bovine serum (Thermo Fisher Scientific, Palm Beach, FL, USA), glutamine (1\%) and the antibiotic gentamicin $(100 \mu \mathrm{g} / \mathrm{mL})$ (Life Technologies, Grand Island, NY, USA). The pIRES2-EGFP plasmid harboring rat TRPV1 cDNA was transiently transfected into HEK-293 cells by replacing the growth medium in each well with a transfection mixture, containing 1.6 $\mathrm{g}$ of DNA and $4 \mu \mathrm{L}$ of Lipofectamine (Life Technologies, Grand Island, NY, USA) in $1 \mathrm{~mL}$ of serum-free DMEM. After incubating for $6 \mathrm{~h}$, the transfection mixture was replaced with normal culture medium. Cells were assayed within $48-96 \mathrm{~h}$ after transfection.

\subsection{Electrophysiology}

Ion currents were recorded using an Axopatch 200A amplifier, with a DigiData 1322A interface, and pClamp8 software (Molecular Devices, Downingtown, PA, USA). External solutions were delivered by a gravity-driven perfusion system at a rate of $0.1 \mathrm{~mL} / \mathrm{s}$. Generally, the whole-cell patch clamp approach was used with recording pipettes containing (mM): $140 \mathrm{CsCl}, 1 \mathrm{MgATP}, 10 \mathrm{BAPTA}$, 10 HEPES-CsOH (pH 7.2). The basic bath solution included the following (mM): $140 \mathrm{NaCl}, 5 \mathrm{KCl}$, $1 \mathrm{MgCl}_{2}, 1 \mathrm{CaCl}_{2}, 10$ HEPES-NaOH (pH 7.4). 


\subsection{Single Cell $\mathrm{Ca}^{2+}$ Imaging}

HEK-293 cells transfected with the pIRES2-EGFP/TRPV1 plasmid were incubated in a bath solution (in mM: $130 \mathrm{NaCl}, 10 \mathrm{NaHCO}_{3}, 5 \mathrm{KCl}, 1 \mathrm{MgCl}_{2}, 1 \mathrm{CaCl}_{2}, 10$ HEPES-NaOH (pH 7.4), 5 glucose) containing $5 \mu \mathrm{M}$ Fura-2AM and $0.02 \%$ Pluronic (both from Life Technologies, Grand Island, NY, USA) for $25 \mathrm{~min}$ at room temperature $\left(23-25^{\circ} \mathrm{C}\right)$. Cells were then rinsed twice with the dye-free bath solution and subjected to 20 min incubation for complete Fura-2AM de-esterification. Next, loaded cells were plated onto a coverslip coated with Cell-Tak (BD Biosciences, Franklin Lakes, NJ, USA) inside an attached ellipsoidal resin chamber (150 $\mu \mathrm{L}$ volume) filled with the bath solution. Cells were stimulated by whole chamber perfusion allowing for the complete change of a chamber solution for $2 \mathrm{~s}$. For acid stimulation, HEPES in the bath solution was substituted for MES, and $\mathrm{pH}$ was adjusted to 5.5. Fura-2 fluorescence was excited at both $340 \mathrm{~nm}$ and $380 \mathrm{~nm}$ using two computer-controlled light emitting diodes (LEDs) (Luxion, Irvine, CA, USA). The Fura-2 emission was recorded at $510 \pm 40 \mathrm{~nm}$ using a Luca R EMCCD camera (Andor Technology, Belfast, UK) attached to an inverted microscope Axiovert $100 \mathrm{~S}$ equipped with a Plan-Neofluar $40 \times / 0.75$ objective (Carl Zeiss, Oberkochen, Germany). Intracellular $\mathrm{Ca}^{2+}$ was evaluated by the ratio of F340/F380, where F340 and F380 are intensities of Fura-2 emission at the excitation of $340 \mathrm{~nm}$ and $380 \mathrm{~nm}$, respectively. EGFP fluorescence was recorded at $525 \pm 40 \mathrm{~nm}$ and excited using a LED (Luxion, Irvine, CA, USA) emitting at $480 \mathrm{~nm}$. All recordings were performed at room temperature.

\subsection{Animals Experiments}

All experiments were performed in accordance with the recommendations in the "Principles of Laboratory Animal Care" and after approval by the Animal Care and Use Committee of the Branch of the IBCh RAS (Pushchino, Russia). Adult male CD-1 mice (Animal Breeding Facility Branch of Shemyakin-Ovchinnikov Institute of Bioorganic Chemistry, Russian Academy of Sciences, Pushchino, Russia) weighing 20-25 g were used. Animals were allowed to acclimate in the laboratory for at least five days. Mice were housed at room temperature $\left(23 \pm 2{ }^{\circ} \mathrm{C}\right)$ on a $12 \mathrm{~h}$ light-dark cycle with food and water available ad libitum. Polypeptides or vehicle was administered intravenously $15 \mathrm{~min}$ before testing.

The significance of the data was determined by analysis of variance (ANOVA) followed by Tukey's test. Data are presented as mean \pm S.E.

\subsubsection{Open-Field Activity in Mice}

Open-field activity was measured using a system that counts interruptions in a set of photo beams (OPTO_VARIMEX (Columbus Instruments, Columbus, OH, USA) and ATM3 Auto System using Auto-Track Version 4.2 software). Spontaneous locomotor activity was recorded for $3 \mathrm{~min}$.

\subsubsection{Hot-Plate Test}

Sensitivity to a thermal stimulus was determined by hind paw withdrawal or licking latency using a Hot-Plate Analgesia Meter (Columbus Instruments, Columbus, OH, USA) at $55{ }^{\circ} \mathrm{C}$. 


\subsubsection{Capsaicin-Induced Acute Pain}

Intraplantar injection of capsaicin (3 $\mu \mathrm{g} / 10 \mu \mathrm{L}$ in $10 \%$ ethanol/90\% saline) was used to elicit capsaicin-induced acute pain [36]. Immediately after the capsaicin injection, mice were placed inside glass cylinders for observation. Intraplantar injection of capsaicin evoked licking and shaking of the injected paw in mice. The duration of episodes of licking and paw shaking were recorded.

\subsubsection{Formalin Test}

Formalin ( $10 \mu \mathrm{L} 2 \%$ in saline) was injected intradermally into the left hind paw. The left hind paw was observed for $60 \mathrm{~min}$ to determine the duration of paw flinching. This test produces a distinct biphasic response [37]. The total duration of paw flinching during the early phase (0-10 min) and late phase (10.01-60 min) were summed.

\subsubsection{Complete Freund's Adjuvant-Induced Thermal Hyperalgesia}

Complete Freund's adjuvant suspended in an oil/saline (1:1) emulsion, was injected into the plantar surface of the left hind-paw of mice $(20 \mu \mathrm{L} /$ paw). Control mice received $20 \mu \mathrm{L}$ of saline (i.pl.). Injected paw withdrawal latencies in response to thermal stimulation $\left(53{ }^{\circ} \mathrm{C}\right)$ were measured $24 \mathrm{~h}$ after CFA injection.

\subsubsection{Acetic Acid-Induced Writhing (Abdominal Constriction Test of Visceral Pain)}

Separate groups of mice were injected with $0.6 \%$ acetic acid in saline $\left(10 \mathrm{~mL} \cdot \mathrm{kg}^{-1}\right.$ intraperitoneally (i.p.)). Mice were immediately placed inside transparent glass cylinders, and the number of writhes was recorded for $15 \mathrm{~min}$.

\subsubsection{Body Temperature Measurements}

The MLT1404 Rectal Temperature Probe and Chart Power Lab (ADInstruments Inc., Colorado Springs, CO, USA) was used to record body temperature. During recording, the animals were placed in a MLA5018 Rodent Restrainer (ADInstruments Inc., Colorado Springs, CO, USA). The adaptation period was $20 \mathrm{~min}$. Core body temperature was recorded every minute for $20 \mathrm{~min}$ before and $100 \mathrm{~min}$ after test compound administration. AMG9810 was dissolved in DMSO and was injected intraperitoneally.

\section{Conclusions}

This study provides evidence that the partial inhibition of TRPV1 in vivo could be more beneficial than its complete inhibition. Polypeptide modulators of TRPV1 showed moderate efficacy in vitro (25\%-30\% block of capsaicin induced current and in the case of APHC3 $\sim 80 \%$ block of pH-induced currents). Nevertheless, both APHC1 and APHC3 proved to have significant antinociceptive and analgesic activity in vivo at low doses $(0.01-0.1 \mathrm{mg} / \mathrm{kg})$. Despite incomplete inhibition of the capsaicin-induced response, APHC1 and APHC3 significantly reduced the pain-related response both in tests directly associated with TRPV1 functions (capsaicin, noxious thermal stimuli, thermal hyperalgesia) and in general models of pain (formalin test, acetic acid writhing). In contrast to the 
majority of TRPV1 antagonists, which provoke marked hyperthermia in vivo, APHC1 and APHC3 caused a moderate decrease in core body temperature. Therefore, the polypeptides APHC1 and APHC3 could be referred to as a new class of TRPV1 modulators that produce a significant analgesic effect without hyperthermia.

\section{Acknowledgments}

We thank Sergey G. Koshelev for electrophysiological measuring of peptides activity on ASIC3 and P2X3 receptors, and Irina V. Mosharova for technical assistance. This work was supported by the Russian Foundation for Basic Research (grants No. 12-04-33151, 12-04-01068, 12-04-90442, 13-04-40082 and 13-04-40080) and the Programs of the Russian Academy of Sciences "Molecular and Cell Biology" and "Fundamental Sciences for Medicine".

\section{Conflicts of Interest}

The authors declare no conflict of interest.

\section{References}

1. Caterina, M.J.; Leffler, A.; Malmberg, A.B.; Martin, W.J.; Trafton, J.; Petersen-Zeitz, K.R.; Koltzenburg, M.; Basbaum, A.I.; Julius, D. Impaired nociception and pain sensation in mice lacking the capsaicin receptor. Science 2000, 288, 306-313.

2. Caterina, M.J.; Schumacher, M.A.; Tominaga, M.; Rosen, T.A.; Levine, J.D.; Julius, D. The capsaicin receptor: A heat-activated ion channel in the pain pathway. Nature 1997, 389, 816-824.

3. Tominaga, M.; Caterina, M.J.; Malmberg, A.B.; Rosen, T.A.; Gilbert, H.; Skinner, K.; Raumann, B.E.; Basbaum, A.I.; Julius, D. The cloned capsaicin receptor integrates multiple pain-producing stimuli. Neuron 1998, 21, 531-543.

4. Szallasi, A.; Cortright, D.N.; Blum, C.A.; Eid, S.R. The vanilloid receptor TRPV1: 10 years from channel cloning to antagonist proof-of-concept. Nat. Rev. Drug Discov. 2007, 6, 357-372.

5. Malmberg, A.; Bley, K. Turning Up the Heat on Pain: TRPV1 Receptors in Pain and Inflammation; Birkhauser Verlag: Basel, Boston, Berlin, 2005.

6. Szallasi, A.; Appendino, G. Vanilloid receptor TRPV1 antagonists as the next generation of painkillers. Are we putting the cart before the horse? J. Med. Chem. 2004, 47, 2717-2723.

7. Gunthorpe, M.J.; Chizh, B.A. Clinical development of TRPV1 antagonists: Targeting a pivotal point in the pain pathway. Drug Discov. Today 2009, 14, 56-67.

8. Gavva, N.R.; Bannon, A.W.; Surapaneni, S.; Hovland, D.N., Jr.; Lehto, S.G.; Gore, A.; Juan, T.; Deng, H.; Han, B.; Klionsky, L.; et al. The vanilloid receptor TRPV1 is tonically activated in vivo and involved in body temperature regulation. J. Neurosci. 2007, 27, 3366-3374.

9. Gavva, N.R.; Treanor, J.J.; Garami, A.; Fang, L.; Surapaneni, S.; Akrami, A.; Alvarez, F.; Bak, A.; Darling, M.; Gore, A.; et al. Pharmacological blockade of the vanilloid receptor TRPV1 elicits marked hyperthermia in humans. Pain 2008, 136, 202-210. 
10. Honore, P.; Chandran, P.; Hernandez, G.; Gauvin, D.M.; Mikusa, J.P.; Zhong, C.; Joshi, S.K.; Ghilardi, J.R.; Sevcik, M.A.; Fryer, R.M.; et al. Repeated dosing of ABT-102, a potent and selective TRPV1 antagonist, enhances TRPV1-mediated analgesic activity in rodents, but attenuates antagonist-induced hyperthermia. Pain 2009, 142, 27-35.

11. Immke, D.C.; Gavva, N.R. The TRPV1 receptor and nociception. Semin. Cell Dev. Biol. 2006, 17, 582-591.

12. Lehto, S.G.; Tamir, R.; Deng, H.; Klionsky, L.; Kuang, R.; Le, A.; Lee, D.; Louis, J.C.; Magal, E.; Manning, B.H.; et al. Antihyperalgesic effects of $(R, E)-N$-(2-hydroxy-2,3-dihydro-1 $H$-inden-4-yl)-3-(2-(piperidin-1-yl)-4-(trifluorom ethyl)phenyl)-acrylamide (AMG8562), a novel transient receptor potential vanilloid type 1 modulator that does not cause hyperthermia in rats. J. Pharmacol. Exp. Ther. 2008, 326, 218-229.

13. Garami, A.; Shimansky, Y.P.; Pakai, E.; Oliveira, D.L.; Gavva, N.R.; Romanovsky, A.A. Contributions of different modes of TRPV1 activation to TRPV1 antagonist-induced hyperthermia. J. Neurosci. 2010, 30, 1435-1440.

14. Andreev, Y.A.; Kozlov, S.A.; Koshelev, S.G.; Ivanova, E.A.; Monastyrnaya, M.M.; Kozlovskaya, E.P.; Grishin, E.V. Analgesic compound from sea anemone Heteractis crispa is the first polypeptide inhibitor of vanilloid receptor 1 (TRPV1). J. Biol. Chem. 2008, 283, 23914-23921.

15. Andreev, Y.A.; Kozlov, S.A.; Kozlovskaya, E.P.; Grishin, E.V. Analgesic effect of a polypeptide inhibitor of the TRPV1 receptor in noxious heat pain models. Dok. Biochem. Biophys. 2009, 424, 46-48.

16. Kozlov, S.A.; Andreev, Y.A.; Murashev, A.N.; Skobtsov, D.I.; D'yachenko, I.A.; Grishin, E.V. New polypeptide components from the Heteractis crispa sea anemone with analgesic activity. Russ. J. Bioorgan. Chem. 2009, 35, 711-719.

17. Philyppov, I.B.; Paduraru, O.N.; Andreev, Y.A.; Grishin, E.V.; Shuba, Y.M. Modulation of TRPV1-dependent contractility of normal and diabetic bladder smooth muscle by analgesic toxins from sea anemone Heteractis crispa. Life Sci. 2012, 91, 912-920.

18. Kozlov, S.; Grishin, E. Convenient nomenclature of cysteine-rich polypeptide toxins from sea anemones. Peptides 2012, 33, 240-244.

19. Antuch, W.; Berndt, K.D.; Chavez, M.A.; Delfin, J.; Wuthrich, K. The NMR solution structure of a Kunitz-type proteinase inhibitor from the sea anemone Stichodactyla helianthus. Eur. J. Biochem. 1993, 212, 675-684.

20. Gebhard, W.; Tschesche, H.; Fritz, H. Biochemistry of aprotinin and aprotinin-like inhibitors. In Proteinase Inhibitors; Barrett, A.J., Salvesen, G., Eds.; Elsevier: Amsterdam, The Netherlands, 1986; pp. 375-388.

21. Creighton, T.E.; Charles, I.G. Sequences of the genes and polypeptide precursors for two bovine protease inhibitors. J. Mol. Biol. 1987, 194, 11-22.

22. Siemens, J.; Zhou, S.; Piskorowski, R.; Nikai, T.; Lumpkin, E.A.; Basbaum, A.I.; King, D.; Julius, D. Spider toxins activate the capsaicin receptor to produce inflammatory pain. Nature 2006, 444, 208-212.

23. Bohlen, C.J.; Priel, A.; Zhou, S.; King, D.; Siemens, J.; Julius, D. A bivalent tarantula toxin activates the capsaicin receptor, TRPV1, by targeting the outer pore domain. Cell 2010, 141, 834-845. 
24. Klionsky, L.; Tamir, R.; Holzinger, B.; Bi, X.; Talvenheimo, J.; Kim, H.; Martin, F.; Louis, J.C.; Treanor, J.J.; Gavva, N.R. A polyclonal antibody to the prepore loop of transient receptor potential vanilloid type 1 blocks channel activation. J. Pharmacol. Exp. Ther. 2006, 319, 192-198.

25. McNamara, C.R.; Mandel-Brehm, J.; Bautista, D.M.; Siemens, J.; Deranian, K.L.; Zhao, M.; Hayward, N.J.; Chong, J.A.; Julius, D.; Moran, M.M.; et al. TRPA1 mediates formalin-induced pain. Proc. Natl. Acad. Sci. USA 2007, 104, 13525-13530.

26. Le Bars, D.; Gozariu, M.; Cadden, S.W. Animal models of nociception. Pharmacol. Rev. 2001, 53, 597-652.

27. Tang, L.; Chen, Y.; Chen, Z.; Blumberg, P.M.; Kozikowski, A.P.; Wang, Z.J. Antinociceptive pharmacology of $N$-(4-chlorobenzyl)- $N$-(4-hydroxy-3-iodo-5-methoxybenzyl) thiourea, a high-affinity competitive antagonist of the transient receptor potential vanilloid 1 receptor. J. Pharmacol. Exp. Ther. 2007, 321, 791-798.

28. Staruschenko, A.; Jeske, N.A.; Akopian, A.N. Contribution of TRPV1-TRPA1 interaction to the single channel properties of the TRPA1 channel. J. Biol. Chem. 2010, 285, 15167-15177.

29. Davis, J.B.; Gray, J.; Gunthorpe, M.J.; Hatcher, J.P.; Davey, P.T.; Overend, P.; Harries, M.H.; Latcham, J.; Clapham, C.; Atkinson, K.; et al. Vanilloid receptor-1 is essential for inflammatory thermal hyperalgesia. Nature 2000, 405, 183-187.

30. Jara-Oseguera, A.; Simon, S.A.; Rosenbaum, T. TRPV1: On the road to pain relief. Curr. Mol. Pharmacol. 2008, 1, 255-269.

31. Ikeda, Y.; Ueno, A.; Naraba, H.; Oh-ishi, S. Involvement of vanilloid receptor VR1 and prostanoids in the acid-induced writhing responses of mice. Life Sci. 2001, 69, 2911-2919.

32. Romanovsky, A.A.; Almeida, M.C.; Garami, A.; Steiner, A.A.; Norman, M.H.; Morrison, S.F.; Nakamura, K.; Burmeister, J.J.; Nucci, T.B. The transient receptor potential vanilloid-1 channel in thermoregulation: A thermosensor it is not. Pharmacol. Rev. 2009, 61, 228-261.

33. Steiner, A.A.; Turek, V.F.; Almeida, M.C.; Burmeister, J.J.; Oliveira, D.L.; Roberts, J.L.; Bannon, A.W.; Norman, M.H.; Louis, J.C.; Treanor, J.J.; et al. Nonthermal activation of transient receptor potential vanilloid-1 channels in abdominal viscera tonically inhibits autonomic cold-defense effectors. J. Neurosci. 2007, 27, 7459-7468.

34. Fosgerau, K.; Weber, U.J.; Gotfredsen, J.W.; Jayatissa, M.; Buus, C.; Kristensen, N.B.; Vestergaard, M.; Teschendorf, P.; Schneider, A.; Hansen, P.; et al. Drug-induced mild therapeutic hypothermia obtained by administration of a transient receptor potential vanilloid type 1 agonist. BMC Cardiovasc. Disord. 2010, 10, 51.

35. Andreev, Y.A.; Kozlov, S.A.; Vassilevski, A.A.; Grishin, E.V. Cyanogen bromide cleavage of proteins in salt and buffer solutions. Anal. Biochem. 2010, 407, 144-146.

36. Sakurada, T.; Katsumata, K.; Tan-No, K.; Sakurada, S.; Kisara, K. The capsaicin test in mice for evaluating tachykinin antagonists in the spinal cord. Neuropharmacology 1992, 31, 1279-1285.

37. Tjolsen, A.; Berge, O.G.; Hunskaar, S.; Rosland, J.H.; Hole, K. The formalin test: An evaluation of the method. Pain 1992, 51, 5-17.

(C) 2013 by the authors; licensee MDPI, Basel, Switzerland. This article is an open access article distributed under the terms and conditions of the Creative Commons Attribution license (http://creativecommons.org/licenses/by/3.0/). 